\title{
Short-Term Tropical Cyclone Intensity Forecasting from Satellite Imagery Based on the Deviation Angle Variance Technique
}

\author{
LIANG HU \\ State Key Laboratory of Severe Weather, Chinese Academy of Meteorological Sciences, Beijing, China, and \\ School of Science, University of New South Wales, Canberra, Australian Capital Territory, Australia \\ ELIZABETH A. RitCHIE \\ School of Science, University of New South Wales, Canberra, Australian Capital Territory, Australia \\ J. SCOTT TYO \\ School of Engineering and IT, University of New South Wales, Canberra, Australian Capital Territory, Australia
}

(Manuscript received 16 May 2019, in final form 7 November 2019)

\begin{abstract}
The deviation angle variance (DAV) is a parameter that characterizes the level of organization of a cloud cluster compared with a perfectly axisymmetric tropical cyclone (TC) using satellite infrared (IR) imagery, and can be used to estimate the intensity of the TC. In this study, the DAV technique is further used to analyze the relationship between satellite imagery and TC future intensity over the North Atlantic basin. The results show that the DAV of the TC changes ahead of the TC intensity change, and this can be used to predict shortterm TC intensity. The DAV-IR 24-h forecast is close to the National Hurricane Center (NHC) 24-h forecast, and the bias is lower than NHC and other methods during weakening periods. Furthermore, an improved TC intensity forecast is obtained by incorporating all four satellite bands. Using SST and TC latitude as the other two predictors in a linear regression model, the RMSE and MAE of the DAV 24-h forecast are 13.7 and $10.9 \mathrm{kt}\left(1 \mathrm{kt} \approx 0.51 \mathrm{~m} \mathrm{~s}^{-1}\right)$, respectively, and the skill space of the DAV is about $5.5 \%$ relative to the Statistical Hurricane Intensity Forecast model with inland decay (Decay-SHIFOR) during TC weakening periods. Considering the DAV is an independent intensity technique, it could potentially add value as a member of the suite of operational intensity forecast techniques, especially during TC weakening periods.
\end{abstract}

\section{Introduction}

Tropical cyclones (TCs) form and spend the majority of their lifetime over the vast tropical oceans. Thus, it is difficult to measure their intensity directly due to the scarcity of traditional measurements (Gray 1979; McBride 1995). However, the development of a suite of satellites that provide almost complete coverage of the vast tropical and subtropical oceans offers a perfect opportunity to observe the TC as never before. Because these observations do not directly measure the wind field or central pressure, techniques have been developed starting with the Dvorak technique (Dvorak 1975), to estimate TC intensity based on cloud pattern detection. While the Dvorak technique is still widely used in operational forecast centers, it is time consuming,

Corresponding author: Liang Hu, hul@cma.gov.cn subjective, and relies heavily on the expertise of the analyst, which can result in widely varying estimates of intensity from the same satellite observations (Velden et al. 1998). More recently the advanced Dvorak technique (ADT), which is an automated alternative to the original Dvorak technique to estimate the intensity of tropical cyclones, was developed (Velden et al. 1998; Olander and Velden 2007). Importantly, ADT removes the reliance of subjective cloud pattern recognition although it does still use visible and IR imagery. Passive microwave (MW) channels allow penetration into precipitating clouds, which is useful when a central dense overcast (CDO) exists in visible and IR images that might mask any eye feature. Satellite passive MW sounders such as the Advanced Microwave Sounding Unit (AMSU) measure the warm-core anomaly, which can be used to estimate TC intensity (Brueske and Velden 2003; Demuth et al. 2004, 2006; Herndon and Velden 2014). In addition, 
passive MW imagers are useful for assessing the distribution of rain, upward motion, and latent heating in TCs, so they can offer unique perspectives to estimating TC intensity. For example, Glass and Felde (1992) found that the percentage of pixels having $85-\mathrm{GHz}$ brightness temperatures below $220-230 \mathrm{~K}$ is highly correlated with TC intensity. Bankert and Tag (2002) described an objective TC intensity estimation method that uses Special Sensor Microwave Imager (SSM/I) 85-GHz imagery and derived rain rates. Tropical Rainfall Measuring Mission (TRMM) Microwave Imager (TMI), Precipitation Radar (PR), and Visible and Infrared Scanner (VIRS) were used together to assess the relationship between intense convection in the inner core and TC intensity change (Kieper and Jiang 2012; Jiang 2012; Jiang et al. 2019). Wimmers et al. (2019) used a deep learning convolutional neural network model to explore whether TC intensity could be estimated using the 37- and $85-92-\mathrm{GHz}$ bands. Olander and Velden (2019) incorporated satellite-based MW information into the ADT, and the result clearly shows an overall reduction in the intensity estimation errors, in particular within the TC intensity ranges most affected by the CDO plateau weak bias.

Contrary to the improvements made in predicting TC track, relatively little progress has been made in forecasting TC intensity and accurate intensity change estimation and forecasting for tropical cyclones is still a considerable research and operational challenge. Since 1990, the National Hurricane Center (NHC) intensity errors in the North Atlantic and eastern North Pacific have decreased by as little as $\sim 1 \mathrm{kt}\left(1 \mathrm{kt} \approx 0.51 \mathrm{~m} \mathrm{~s}^{-1}\right)$ for the 24-h intensity forecast and by only $5 \mathrm{kt}$ for the 48 -h forecast. Although intensity change remains one of the most difficult aspects of tropical cyclone forecasting, objective guidance has shown some improvement. The greatest improvement is realized when consensus methods are utilized, especially those that blend statistical-dynamical based guidance with dynamical ocean-coupled regional models (Sebastien et al. 2018). Therefore, techniques (e.g., the Statistical Hurricane Intensity Prediction Scheme and its rapid intensification index) that utilize satellite data in predicting changes in intensity are an important complement to TC intensity forecast.

TCs are a prolific producer of convective clouds. The convective towers build far into the troposphere and sometimes penetrate the lower stratosphere. Latent heat is released when the warm moist tropical air ascends in major cumulus towers, and it is the primary fuel for the TCs (Dunn and Miller 1960). The latent heat is ultimately converted to kinetic energy, which causes the extreme winds of the tropical cyclones (Riehl 1954). To do this, complex processes are involved including, among other things, conversion of the heat to potential and available energy. These processes take time; therefore, there is a lag between changes in convective activity and changes of maximum winds in the storm. The results of theoretical numerical model experiments in simulating development and maintenance of tropical cyclones support the reasoning and suggest that maximum vertical motion (i.e., maximum convection) precedes the highest winds by 1-3 days (Kurihara and Tuleya 1974; Rosenthal 1978). Riehl (1954) and Rosenthal (1978) have also emphasized that the convection needs to be organized by some largescale system into a suitable pattern (e.g., spiral bands and eyewall) before rapid intensification of the tropical cyclone takes place. Thus, imagery information on the extent and strength of the convection can serve as indicators of the latent heat released and inform the extent to which the clouds of the storm are organized into patterns ahead of actual intensity changes.

These previous studies provide theoretical knowledge to predict TC intensity using satellite imagery, and earlier investigators have used satellite imagery to suggest future changes of the TC intensity. As MW imagery has the capability to monitor convective bursts, hot towers, and rain, it has been used to study trends in TC intensity. For example, using 1995-96 brightness temperature for the vertically and horizontally polarized channel at $85 \mathrm{GHz}$, a correlation coefficient of -0.73 is shown between $0^{\circ}$ and $1^{\circ}$ radius polarization corrected temperature (PCT) parameters and 24-h future hurricane intensity over the North Atlantic (Cecil and Zipser 1999). In addition, MW imagery produces a $2 \%-8 \%$ improvement in performance for the Atlantic TC intensity forecast in SHIPS (Jones et al. 2006). In addition to MW imagery, strong correlations also exist between TC intensity changes and IR and water vapor (WV) values. Olander and Velden (2009) found that the correlation coefficients between the pixel count of the IR-WV channel brightness temperature difference $<0$ and mean sea level pressure (MSLP) $24 \mathrm{~h}$ later is 0.66 . These studies suggest that satellite data can be used to help predict the intensity of tropical cyclones, especially with the increasing availability of higher-quality satellite data.

The deviation angle variance (DAV) is a parameter that characterizes the level of organization of a cloud cluster compared with a perfectly axisymmetric TC using satellite IR imagery (Piñeros et al. 2008, 2011). The DAV technique (DAV-T) quantifies the level of axisymmetry of a cloud cluster relative to an idealized TC in IR imagery by performing a statistical analysis of the direction of the gradient of the IR brightness temperatures. The brightness temperature gradient vectors of an axisymmetric $\mathrm{TC}$ are more aligned along radials extending from the TC center than the vectors computed from a weak, disorganized tropical system. Thus, the variance of the 
deviation angle between the radial and every brightness temperature gradient vector within some defined radius of the TC center, quantifies the degree of storm organization. Piñeros et al. (2008) showed that the variance of the DAV is negatively correlated with TC intensity for 26 TC cases during the 2005 North Atlantic hurricane season. An updated version, which used the National Hurricane Center (NHC) best track archive to center the algorithm, yielded significant improvements for specific sheared TC cases (Ritchie et al. 2012). More recently, the effect of satellite observation angle on the DAV TC intensity estimation was analyzed and an improvement of $0.9 \mathrm{kt}$ in RMSE for all TCs and $5.4 \mathrm{kt}$ for major hurricanes to the DAV TC intensity estimation was documented in Hu et al. (2019). The DAV method has proven to be robust across all TC basins to which it has been applied, with results in the western (Ritchie et al. 2014) and eastern (Wood et al. 2015) North Pacific Oceans, as well as the Australian TC basins (unpublished data). Performance of the DAV method is also platform agnostic, as equivalent results have been obtained using NOAA's GOES-E and GOES-W satellites (Piñeros et al. 2008; Ritchie et al. 2014), the Japanese Meteorological Agency's MTSAT and Himawari satellites (Wood et al. 2015), and recently the Chinese Fengyun-2E and Fengyun- $2 F$ satellites (Hu et al. 2019). Based on these new developments, the lead time of satellite-based cloud structural organization (DAV) to TC intensity is tested and used as a predictor of short-term TC intensity in this study. The rest of the paper is organized into 3 sections. The datasets and methods used in the study are introduced in the next section. In section 3, the TC intensity forecast using IR imagery and multiband satellite imagery is presented and compared with the NHC forecast. Section 4 provides a summary and conclusions.

\section{Data and methodology}

\section{a. Data}

A total of 7 years of Geostationary Operational Environmental Satellite imagery (GOES-12 for 2009, GOES-13 for 2010-15) from the North Atlantic tropical cyclone season were collected and rectified as described in Ritchie et al. (2012). These satellite images include 10.7- $\mu \mathrm{m}$ longwave IR, $6.48-\mu \mathrm{m} \mathrm{WV}$, shortwave window $(3.9 \mu \mathrm{m})$, and $\mathrm{CO}_{2}$ band $(13.3 \mu \mathrm{m})$ imagery, with a $4-\mathrm{km}$ nadir resolution and 30-min interval (Hillger and Schmit 2010). Tropical cyclone best track data, the 24-h TC intensity forecast from NHC's official output, and Statistical Hurricane Intensity Forecast model with inland decay (Decay-SHIFOR) output (6-h intervals) were spline interpolated to match the satellite temporal resolution. The times when the TC intensity was less than $34 \mathrm{kt}$ or the TC center passed over continents and large islands were removed, as was done in previous studies (Ritchie et al. 2012, 2014). The final dataset comprises 109 tropical cyclones and a total of 21802 images, in which $49.5 \%$ are tropical storm intensity, $20.6 \%$ are hurricane intensity, and $5.4 \%$ are major hurricane intensity.

\section{b. Method}

The DAV at the best track TC center is calculated and used to forecast the TC intensity in this study (Ritchie et al. 2012). The DAV is calculated over a circular area within a given radius from the center of the TC. To test for sensitivity to this area of calculation, the DAV value is calculated using eight different radii from the center (150 through $500 \mathrm{~km}$, every $50 \mathrm{~km}$ ). All DAV values of tropical cyclones with wind speeds greater than or equal to $34 \mathrm{kt}$ from 2009 to 2015 are used to forecast the TC intensity based on Eq. (1) from Ritchie et al. (2012):

$$
f(\mathrm{DAV})=\frac{140}{1+e^{[a(\mathrm{DAV}-b)]}}+25,
$$

where DAV is the DAV value at the TC center calculated from satellite images; $a$ and $b$ are two parameters established by minimizing the RMSE relative to best track, which represent the slope and shift of the sigmoid curve, respectively.

Next, as described by Hu et al. (2019), the effect of the satellite observation angle on the DAV of the IR, WV, 3.9- $\mu \mathrm{m}$ and $13.3-\mu \mathrm{m}$ imagery, and their impact on the TC intensity forecast are considered. The RMSE, Pearson correlation coefficient (PCC), Spearman rank correlation coefficient (SCC), mean absolute error (MAE), and mean relative error (MRE) between the DAV-based TC intensity forecast and the NHC best track dataset are calculated and compared with NHC's TC intensity forecast.

\section{Results}

\section{a. TC intensity forecast using the DAV technique}

To fit the highly smoothed interpolated best track intensity, we have previously used a low-pass filter (impulse response: $e^{-t / \tau}$ with a filter time constant of $\tau=100 \mathrm{~h}$ ) to smooth the original DAV time series (Piñeros et al. 2008, 2011; Ritchie et al. 2012, 2014). The filter successfully reduces the high-frequency oscillations in the DAV time series, but it also eliminates lead-time information in the satellite data and even introduces a time delay in rapidly intensifying cases (Ritchie et al. 2012).

Numerous studies have documented the existence of diurnal maxima and minima associated with tropical oceanic convection and the TC upper-level cirrus canopy (Kossin 2002; Dunion et al. 2014, 2019). These diurnal 
(a)

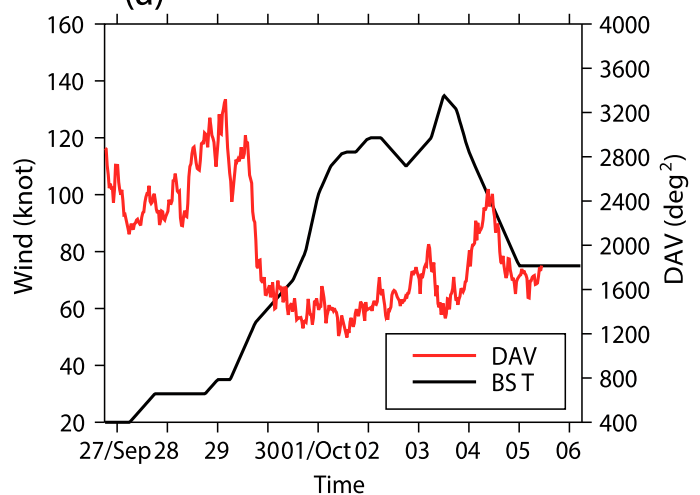

(b)

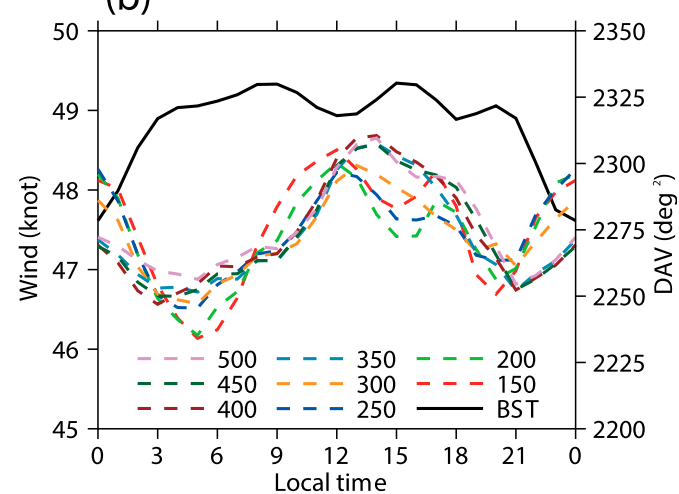

(c)

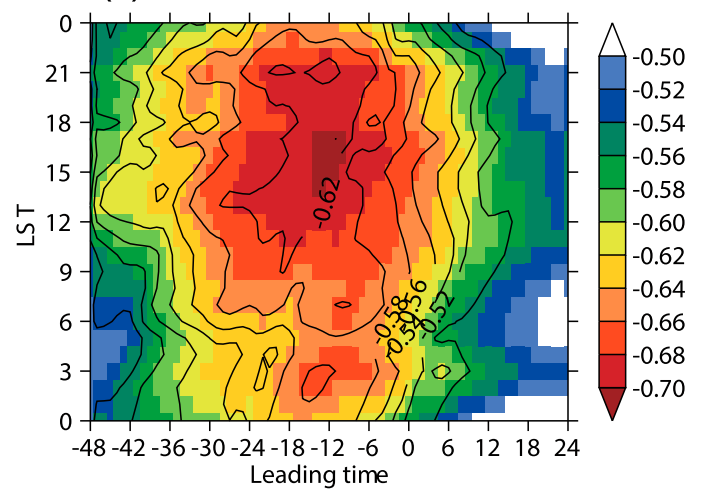

FIG. 1. (a) The time series of 500-km DAV vs wind speed for Hurricane Joaquin (2015), (b) the diurnal cycle of the DAV value calculated using eight radii of calculation (color dashed; km) and TC maximum surface wind speed (solid black) for 109 tropical cyclones during 2009-15 in the North Atlantic Ocean, and (c) the lead time vs local time correlation coefficient between the 400-km DAV-IR and TC best track intensity. Shading and contours indicate PCC and SCC, respectively.

and semidiurnal fluctuations are captured in the DAV for all 109 North Atlantic TCs (Figs. 1a,b). Based on Hu et al. (2019), a 24-h DAV mean can be selected to eliminate these diurnal and semidiurnal variations, and the 24-h backward DAV mean has lower error (RMSE, MAE, MRE) and higher correlation (PCC and SCC) than the 24-h centered DAV mean, which indicates that changes in the TC cloud structure lead the actual TC intensity. To demonstrate this lead time effect, the lead time versus local time cross section of the correlation coefficient between the $400-\mathrm{km}$ DAV calculated using IR imagery (DAV-IR) with TC intensity is shown in Fig. 1c. Higher correlation coefficients $(\leq-0.6)$ between the DAV-IR and TC intensity occur between -36 - and 6-h lead times, indicating that changes in the DAV value lead the TC intensity with a lead time that is consistent with Rosenthal (1978) and Olander and Velden (2009). The correlation between lead time and local time also exhibits diurnal and semidiurnal fluctuations with a maximum correlation at 1200-1800 LST (Fig. 1c). To reduce the fluctuation but retain a maximum amount of lead time information, the
6-, 12-, 18-, and 24-h DAV averages are used in turn to produce the 0-, 6-, 12-, 24-, and 30-h TC intensity forecast and these are then tested for accuracy. For example, to produce a 24 -h forecast of the intensity of Hurricane Igor (2010) at 0000 UTC 15 September 2010, the 6-h DAV mean would be calculated from 1800 UTC 13 September to 0000 UTC 14 September, the 12-h DAV mean would be calculated from 1200 UTC 13 September to 0000 UTC 14 September, and so on up to the 24-h DAV mean from 0000 UTC 13 September to 0000 UTC 14 September and these means would be used separately to produce the intensity forecast valid at 0000 UTC 15 September 2010 and the errors calculated.

The DAV mean values versus future best track intensity are plotted for 6 combinations in Fig. 2 along with the best-fit sigmoid relationship. Figure 2 suggests that a mean DAV value 12 or $24 \mathrm{~h}$ prior is highly related with TC intensity although the RMSE and MAE increase and the PCC decreases with forecast lead time. Furthermore, the 24-h mean DAV produces a lower error and higher correlation than the 12 -h mean DAV 
12 hr mean
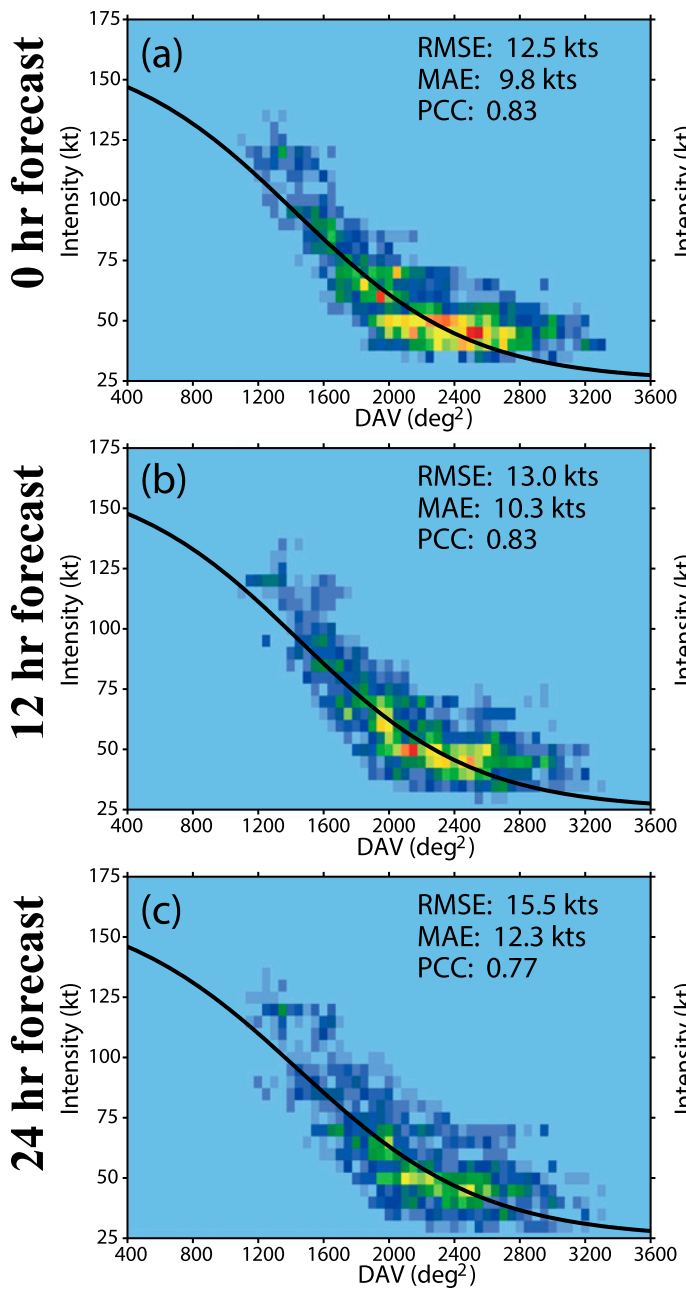

24 hr mean

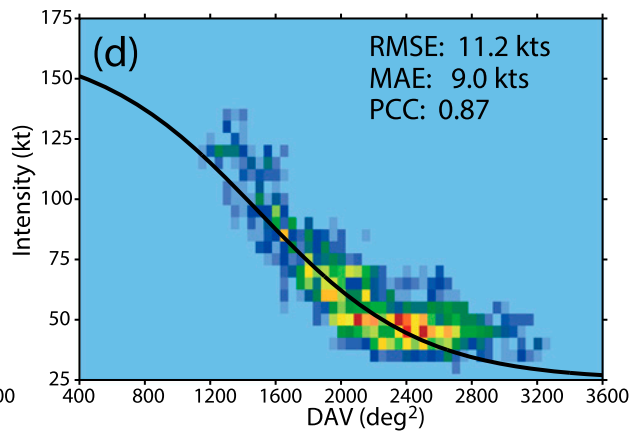

145

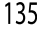

125
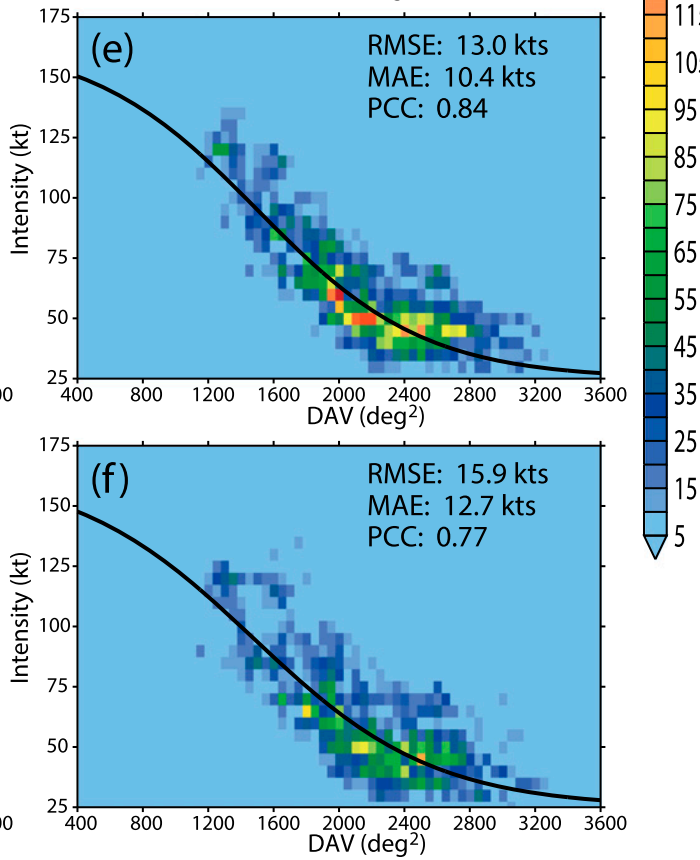

FIG. 2. Scatterplot of DAV-IR mean vs interpolated best track maximum wind speeds (a) from -12 to $0 \mathrm{~h}$, (b) from -24 to $-12 \mathrm{~h},(\mathrm{c})$ from -36 to $-24 \mathrm{~h}$, (d) from -24 to $0 \mathrm{~h}$, (e) from -36 to $-12 \mathrm{~h}$, and (f) from -48 to $-24 \mathrm{~h}$ for a radius of $400 \mathrm{~km}$ during 2009-15. The shading indicates the number of TC samples. The black solid curve is the sigmoid fit of the DAV-intensity relationship for these data. The RMSE, MAE, and PCC are shown at the upper right of each panel.

for real-time TC intensity estimation. In contrast, the 12-h mean DAV produces lower errors than the 24-h mean DAV for the 12- and 24-h TC intensity forecasts.

The satellite observation angle also impacts the DAV calculation and resulting intensity estimation, so we have included the satellite-angle-based intensity estimator methodology reported in $\mathrm{Hu}$ et al. (2019). Figure 3 shows the errors and correlation between the DAV 24-h forecast and the best track at all eight radii of DAV calculation after the satellite observation angle effect is considered. The RMSE and MAE decrease, and PCC increases from 150 to $400 \mathrm{~km}$ radius of calculation and then all quantities remain stable from 400 to $500 \mathrm{~km}$ radius of calculation. Thus, for the remainder of this paper only the results using a radius of DAV calculation of $400 \mathrm{~km}$ will be shown. It should be noted that the best radius for calculating the DAV for TC intensity forecasting is larger than that for DAV TC current intensity estimation (300 km, Ritchie et al. 2012; Hu et al. 2019).

Table 1 shows the RMSE, MAE and PCC for the 6-, 12-, 18-, 24-, and 30-h intensity forecasts using the 6-, 12-, 18-, and 24-h mean DAV, respectively. Longer time forecasts are more accurate when shorter time-mean DAV is used. This is because the information in the TC cloud structure that is highly correlated with intensity occurs within $36 \mathrm{~h}$ (Fig. 1b). Thus, when imagery outside this time window is used, noise is introduced into the DAV mean, which degrades the forecast. Furthermore, 


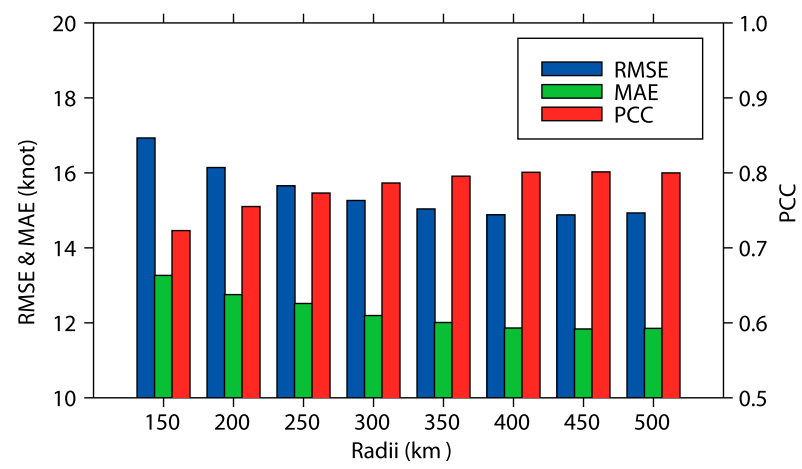

FIG. 3. The RMSE, MAE, and PCC of the 24-h intensity forecast produced using the 12 -h mean DAV from IR imagery at the eight different radii of DAV calculation.

Fig. 1b suggests that the correlation between the DAV with TC intensity is maximized using the DAV calculated at $1200-1800$ LST. Thus, results for intensity forecasts using the 1200-1800 LST mean DAV only are also shown in Table 1 . When the forecast lead time is longer than $12 \mathrm{~h}$, the 1200-1800 LST mean DAV has the best performance in RMSE, MAE, and PCC compared to the other DAV means. To simplify the discussion for the rest of the paper, only the 24-h intensity forecast using the 12 -h DAV mean is analyzed and compared to the NHC 24-h intensity forecast.

\section{$b$. The 24-h TC intensity forecast using IR imagery based on $D A V-T$}

Based on section 3a, 12-h mean 400-km DAV values calculated using IR imagery are used to produce a $24-\mathrm{h}$ TC intensity forecast for all TCs during 2009-15 in the North Atlantic basin.

The 24-h forecast errors and correlations by year for the period 2009-15 are shown in Table 2. For both the DAV forecasts and the NHC forecasts, the highest correlations occur in 2009 and 2015, while the lowest correlations occur in 2012 and 2013, where the TCs were generally weaker than normal. Compared with other short-term forecast techniques, the MAE $(11.9 \mathrm{kt})$ of the DAV forecast technique is lower than the Dvorak-based technique (13 kt; Arnold 1974), but higher than the statistical model SHIPS (9kt) and SHIPS + PCT- $85 \mathrm{GHz}$ (8.6 kt; Jones et al. 2006) although the study period is different. The correlation (0.78) for the DAV technique is higher than for PCT85-GHz (0.73; Cecil and Zipser 1999) and the IR-WV brightness temperature difference (0.66; Olander and Velden 2009). It is noteworthy that the statistical values of all TCs in Table 2 are slightly different to those shown in Table 1 because the number of TC samples is different due to missing values in the NHC forecast archives at the beginning of each TC.

To take a closer look at potential weaknesses in the DAV intensity forecast scheme, and to highlight improvements, the year that exhibits the highest RMSE in Table 2 for both the DAV scheme and the NHC official forecasts (2010) was chosen for further analysis. Figure 4 shows the 24-h TC intensity forecast comparison between the NHC forecast and the DAV-based forecast for the 12 hurricanes that occurred in 2010. The systems that reached hurricane intensity are specifically chosen since they exhibit the full range of intensity values and are more likely to emphasize if errors are due to the higher or lower intensity periods. In Fig. 4 the predicted intensity and its variation using the DAV-IR technique correlate very well with both the actual best track intensity and the NHC 24-h prediction. The RMSE, PCC, SCC, MAE, and MRE between the 24-h DAV-IR (NHC) intensity forecast and the best track intensity is $16.0(14.8), 0.82(0.87), 0.82(0.87), 12.8(11.2) \mathrm{kt}$ and $18.2 \%(17.1 \%)$, respectively. Compared to the NHC forecast and the best track, the DAV-IR appears to have a low bias relative to both the best track and the NHC official forecast at the highest intensities but does appear to better capture periods of weakening. Furthermore, there are higher-frequency oscillations present in the DAV intensity forecast due to the higher time resolution satellite imagery used, which contributes to a higher error and lower correlation. These higher-frequency signals may be real, so the estimates of error relative to the highly smoothed NHC forecast and best track data are worst-case estimates.

TABLE 1. The RMSE, MAE, and PCC of intensity forecasts during 2009-15 using 6-h, 12-h, 18-h, 24-h, and 1200-1800 LST mean 400-km DAV, respectively. Each entry is ordered (RMSE/MAE/PCC). The lowest error and highest correlation are highlighted in boldface italics. All correlations were significant at the 0.001 level using a Student's $t$ test.

\begin{tabular}{clllll}
\hline \hline & \multicolumn{5}{c}{ Time forecast } \\
\cline { 2 - 6 } Time mean & \multicolumn{1}{c}{$6 \mathrm{~h}$} & \multicolumn{1}{c}{$12 \mathrm{~h}$} & \multicolumn{1}{c}{$18 \mathrm{~h}$} & \multicolumn{1}{c}{$24 \mathrm{~h}$} & \\
\hline $6 \mathrm{~h}$ & $13.0 / 10.1 / 0.81$ & $13.4 / 10.4 / 0.81$ & $14.1 / 11.1 / 0.80$ & $15.1 / 11.9 / 0.78$ & $16.1 / 12.7 / 0.76$ \\
$12 \mathrm{~h}$ & $12.1 / 9.5 / 0.84$ & $12.7 / 10.1 / 0.84$ & $13.7 / 10.8 / 0.82$ & $\mathbf{1 4 . 8 / 1 1 . 8 / 0 . 8 0}$ & $\mathbf{1 6 . 0 / 1 2 . 6 / 0 . 7 7}$ \\
$18 \mathrm{~h}$ & $11.6 / 9.3 / 0.86$ & $\mathbf{1 2 . 5 / 1 0 . 0 / 0 . 8 5}$ & $\mathbf{1 3 . 6 / 1 0 . 9 / 0 . 8 2}$ & $14.9 / 11.8 / 0.80$ & $16.2 / 12.7 / 0.77$ \\
$24 \mathrm{~h}$ & $\mathbf{1 1 . 5 / 9 . 3 / 0 . 8 6}$ & $12.6 / 10.1 / 0.85$ & $13.8 / 11.0 / 0.82$ & $15.1 / 11.9 / 0.80$ & $16.4 / 12.8 / 0.77$ \\
$12-18$ LST & $12.0 / 9.4 / 0.82$ & $13.0 / 10.2 / 0.83$ & $13.5 / 10.5 / 0.82$ & $14.6 / 11.5 / 0.81$ & $15.8 / 12.2 / 0.76$ \\
\hline
\end{tabular}


TABLE 2. The 24-h forecast errors and correlations by year (DAV/NHC). The DAV forecast is calculated using the 12-h mean 400-km DAV. All correlations are significant at the 0.001 level using a Student's $t$ test.

\begin{tabular}{|c|c|c|c|c|c|c|}
\hline Year & No. of samples & PCC & SCC & RMSE (kt) & MAE (kt) & MRE (\%) \\
\hline 2009 & 473 & $0.94 / 0.91$ & $0.93 / 0.90$ & $10.2 / 13.1$ & $8.0 / 11.2$ & $11.3 / 17.4$ \\
\hline 2010 & 1518 & $0.81 / 0.87$ & $0.82 / 0.87$ & $16.4 / 14.8$ & $13.2 / 11.2$ & 19.2/17.1 \\
\hline 2011 & 1781 & $0.71 / 0.82$ & $0.63 / 0.78$ & 14.8/11.9 & 11.6/9.1 & $19.8 / 14.5$ \\
\hline 2012 & 1823 & $0.31 / 0.67$ & $0.34 / 0.69$ & $16.0 / 10.7$ & $13.1 / 8.0$ & $20.3 / 12.6$ \\
\hline 2013 & 660 & $0.44 / 0.66$ & $0.32 / 0.72$ & $11.7 / 7.3$ & $9.5 / 5.6$ & 24.9/14.0 \\
\hline 2014 & 787 & $0.84 / 0.89$ & $0.79 / 0.87$ & $16.2 / 11.0$ & $14.0 / 8.7$ & $18.3 / 11.8$ \\
\hline 2015 & 710 & $0.89 / 0.91$ & $0.75 / 0.83$ & $13.8 / 12.1$ & 9.9/8.9 & $16.2 / 13.9$ \\
\hline All & 7752 & $0.78 / 0.87$ & $0.71 / 0.86$ & $15.0 / 12.0$ & $11.9 / 9.0$ & $19.2 / 14.4$ \\
\hline
\end{tabular}

The errors in the DAV forecast for different TC intensity categories are shown in Table 3. For both the DAV technique and NHC, the RMSE and MAE of the 24-h TC intensity forecast increases with increasing TC intensity category, similar to that for current TC intensity estimation using the DAV (Ritchie et al. 2014; Hu et al. 2019). This increasing error with increasing intensity also explains some of the results in Table 2. Because there were only two hurricanes in 2013, and the satellite imagery for those cases were missing, only tropical storm intensity TCs are included in the 2013 statistical analysis. The 2013 season exhibits the lowest RMSE and MAE of all years. In addition, from tropical storm to major hurricane intensities, the error difference between the DAV and NHC increases from 2.1 to $5.8 \mathrm{kt}$, which suggests that the DAV intensity forecast is worse than the NHC for major hurricane intensities. This phenomenon is caused mainly by two factors, which have been discussed by Ritchie et al. (2012). First, the DAV-T parametric curve is fitted to obtain the smallest RMSE over all TC samples, but there are always many more samples at weaker intensities than for major hurricane intensities. This causes the curve to be fitted more closely to the weaker intensity samples. The other factor is that the bounding of the two ends of the sigmoid curve leads to a systematic overestimation at the low intensity end and underestimation at the high intensity end of the scale.

The DAV's 24-h forecast performance is also investigated according to whether the TC is intensifying, decaying, or in steady-state maintenance (Table 4). For all TC samples, the TC stage is defined as follows:

$$
\begin{array}{ll}
\text { intensification: } & v>\mu+0.5 \sigma, \\
\text { maintenance: } & \mu+0.5 \sigma>v>\mu-0.5 \sigma, \\
\text { weakening: } & v<\mu-0.5 \sigma,
\end{array}
$$

where $v$ is the time variance of the TC intensity, $\mu$ is the mean $v$ of all TC samples, $\sigma$ is the standard variance of $v$.

As shown in Table 4, it is clear that the RMSE and MAE difference between the DAV and NHC intensity forecasts is much smaller during the weakening stage than intensification and maintenance stages. The bias of the DAV is smaller and is opposite to NHC during weakening periods. However, the Dvorak TC intensity estimation and other intensity forecasts usually produce a large bias during weakening periods (Knaff et al. 2010). This is illustrated in Fig. 4 where the DAV forecast errors in TCs Igor (2010) and Tomas (2010) are smaller than NHC during the weakening periods. During weakening periods, the TC is more likely to be affected by midlatitude weather systems, and the interaction between the TC and these weather systems can be partly detected by IR and thus quantified in the DAV. However, the same interactions can be problematic for operational forecast models producing higher errors than other times in the TC life cycle (e.g., Harr et al. 2008). This results in a better DAV forecast performance compared to the NHC during weakening periods and suggests that the DAV can provide complementary information to improve TC intensity forecasts during weakening periods.

Figure $5 \mathrm{a}$ is the 24-h forecast bias for both the DAV-IR and NHC by TC intensity. The bias distribution is similar between DAV-IR and NHC, with both overestimating intensity for tropical storms but underestimating for

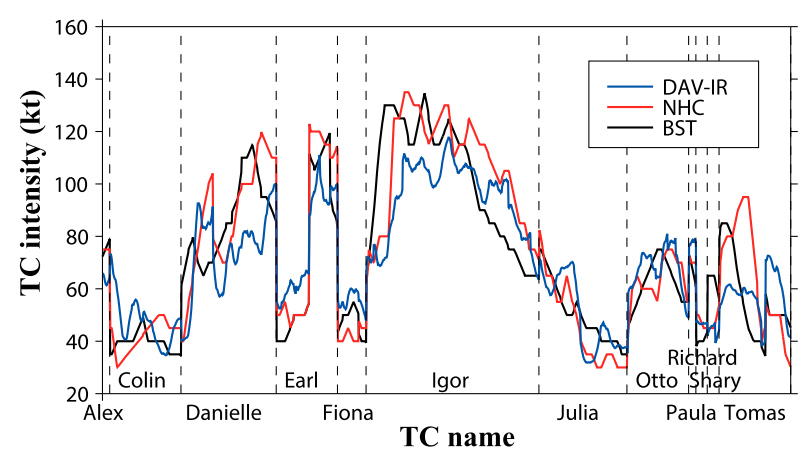

FIG. 4. The 24-h TC intensity forecast produced using the 12-h mean 400-km DAV-IR compared with the NHC 24-h intensity forecast and the best track intensity for 12 hurricanes (1518 samples $\geq 34 \mathrm{kt}$ ) in 2010 . The samples are split evenly and do not represent a time-continuous plot. 
TABLE 3. The 24-h intensity forecast errors by TC intensity range (DAV/NHC). The DAV is calculated as the 12-h mean 400-km DAV and the difference between the DAV and NHC forecast errors were significant at the 0.01 level using a Student's $t$ test.

\begin{tabular}{|c|c|c|c|c|}
\hline TC intensity & No. of samples & RMSE (kt) & MAE (kt) & MRE (\%) \\
\hline Tropical storms & 4398 & $11.1 / 9.0$ & $9.1 / 6.8$ & 19.6/14.7 \\
\hline Hurricane categories 1-2 & 2390 & $17.5 / 15.0$ & $14.7 / 12.2$ & 19.3/15.7 \\
\hline Hurricane categories $3-5$ & 964 & $21.3 / 15.5$ & $17.4 / 12.3$ & $15.4 / 10.9$ \\
\hline
\end{tabular}

hurricane categories 1-5. In general, the NHC's forecast result is better than the DAV-IR for all TC intensity bins, which is not surprising considering the $\mathrm{NHC}$ forecast is made from many different sources of information. The largest forecast difference between NHC and DAV-IR occurs at $110 \mathrm{kt}$. The probability density function (PDF) and cumulative distribution function (CDF) of the absolute error of the 24-h intensity forecast for the DAV-IR and NHC shows that there are more samples with absolute error within $6 \mathrm{kt}$ for NHC, and more samples with absolute error within 12-20 and $25-35 \mathrm{kt}$ for the DAV (Fig. $5 \mathrm{~b}$ ). Half of the DAV-IR forecast errors are within $10 \mathrm{kt}, 75 \%$ are within $16 \mathrm{kt}$, and $90 \%$ are within $24 \mathrm{kt}$, close to the 6 , 12 , and $20 \mathrm{kt}$ for the NHC forecast, respectively.

\section{c. 24-h TC intensity forecast based on multiband imagery}

The satellite bands including IR $(10.7 \mu \mathrm{m})$, WV $(6.7 \mu \mathrm{m}), 3.9 \mu \mathrm{m}$, and $13.3 \mu \mathrm{m}$ sense different atmospheric characteristics, and they exhibit different characteristics in DAV-based TC intensity estimation. Therefore, the impact of these four satellite bands on the DAV-TC intensity forecast is investigated. The visible channel is currently excluded because there are no observations at night.

First, the effect of the satellite observation angle on the DAV calculation and the TC intensity forecast is checked for all four bands to confirm whether a similar impact occurs in the other bands as with the IR (Hu et al. 2019). The TC images are divided into four groups according to observation angles: $0^{\circ}-25^{\circ} ; 25^{\circ}-30^{\circ} ; 30^{\circ}-35^{\circ}$, and $35^{\circ}-45^{\circ}$, and sigmoid fit curves are calculated for each group (Fig. 6). Similar to the results for IR imagery, as the satellite observation angle increases, the sigmoid fit curve flattens for all bands. That is, for a fixed DAV value, the TC intensity estimation decreases as the satellite observation angle increases, especially when the DAV value is low.
Therefore, the effect of the satellite observation angle is included in these multiband results. In addition, similar to the results in section 4, the DAV for all bands is calculated over the eight areas with a radius extending from 150 to $500 \mathrm{~km}$ at $50 \mathrm{~km}$ to test for sensitivity to the DAV due to the area of calculation. Finally, the RMSE, MAE, PCC, and SCC of the 0-, 6-, 12-, 18-, 24-, and 30-h intensity forecast using 6-, 12-, 18- and 24-h mean DAV are calculated for all bands and analyzed. Since the RMSE and MAE are similar to each other, and the PCC and SCC are similar to each other, only the RMSE and PCC are shown in Fig. 7.

From Fig. 7, the RMSE increases and the PCC decreases as the intensity forecast lead time increases. There is clear spread in performance between the bands with the 18-24-h mean IR DAV performing the best when the forecast lead time is within $12 \mathrm{~h}$. At $18 \mathrm{~h}$ lead time, the IR and $13.3 \mu \mathrm{m}$ perform similarly. However, when the forecast lead time is greater than $18 \mathrm{~h}$, the performance of all bands becomes more similar with the 6-12-h mean 13.3- $\mu \mathrm{m}$ DAV calculated over an area with a radius of $400 \mathrm{~km}$ just out-performing the other three bands. These results are again similar to those previously shown with a longer mean DAV appropriate for shorter forecast lead times and a shorter mean DAV appropriate for longer forecast lead times.

The 24-h intensity forecast for all bands is separated by TC intensity, and the radii of calculation versus RMSE are shown in Fig. 8. For different TC intensities, different bands with different radii of calculation produce a better TC intensity forecast. For example, for tropical storms, the $400-500-\mathrm{km}$ radii of DAV calculation produce the lowest error. However, for category 2, a small area of calculation with a radius of $200-300 \mathrm{~km}$ produces the lowest errors. Thus, the 400-km DAV from $13.3 \mu \mathrm{m}$ (TS), 400-km DAV from $13.3 \mu \mathrm{m}$ (category 1), 300-km DAV from $13.3 \mu \mathrm{m}$ (category 2), 400-km DAV from $13.3 \mu \mathrm{m}$ (category 3), and 350-km DAV from $3.9 \mu \mathrm{m}$ (categories 4-5)

TABLE 4. The 24-h intensity forecast errors by TC intensity stage (DAV/NHC). The DAV is calculated as the 12-h mean 400-km DAV and the difference between the two forecast errors are significant at the 0.01 level using a Student's $t$ test.

\begin{tabular}{|c|c|c|c|c|c|}
\hline TC stage & No. of samples & RMSE (kt) & MAE (kt) & MRE (\%) & Bias (kt) \\
\hline Intensification & 2038 & $18.4 / 13.4$ & $14.9 / 10.1$ & $20.5 / 13.8$ & $-9.9 /-6.8$ \\
\hline Maintenance & 3648 & $13.6 / 10.4$ & $10.9 / 7.9$ & 19.7/14.1 & $0.3 / 1.3$ \\
\hline Weakening & 2066 & 13.6/13.1 & $10.9 / 9.9$ & $17.0 / 15.3$ & $-1.1 / 4.9$ \\
\hline
\end{tabular}



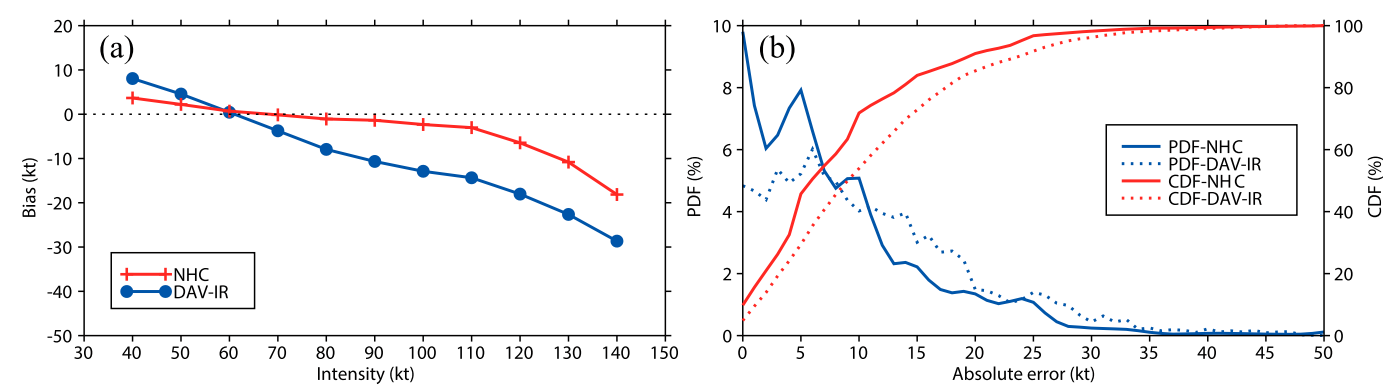

FIG. 5. (a) Bias for the DAV and NHC 24-h TC intensity forecasts plotted as a function of TC intensity and (b) the $\mathrm{PDF}$ and $\mathrm{CDF}$ distributions for the absolute error in the DAV and NHC intensity forecasts.

produce the lowest error and highest correlation, respectively. Using this combination, an improved 24-h TC intensity forecast based on the DAV multiband imagery (DAV-Bands) is obtained. Compared to the forecast using IR imagery only (DAV-IR), the RMSE, MAE, and MRE decrease from $15.0 \mathrm{kt}, 11.9 \mathrm{kt}$, and $19.2 \%$ to $14.5 \mathrm{kt}, 11.4 \mathrm{kt}$, and $18.5 \%$, respectively, using DAVBands for all TC samples, with improvements for all TC intensity bins (Table 5). A comparison of the 24-h intensity prediction using the DAV-Bands compared with the NHC forecast and the best track is shown in Fig. 9 for 2010 (Fig. 9a) and all years (Fig. 9b).

The DAV-Bands 24-h intensity forecast bias is shown in Fig. 10a. DAV-Bands still overestimates the intensity of tropical storms and underestimates hurricanes, but compared to the DAV-IR, the bias is improved in DAVBands, especially for hurricane categories 4 and 5. The largest improvement is about $2 \mathrm{kt}$. The largest forecast difference between NHC and DAV-Bands is still at approximately $110-\mathrm{kt}$ intensity but the difference has decreased by almost $1 \mathrm{kt}$ over the 7 years. The PDF and CDF of the absolute error of the 24-h intensity forecast show that half of the DAV-Bands forecast errors are within $9 \mathrm{kt}, 75 \%$ are within $16 \mathrm{kt}$, and $90 \%$ are within $23 \mathrm{kt}$, better than DAV-IR (10, 16, and $24 \mathrm{kt})$, but still $3 \mathrm{kt}$ higher than the NHC forecast $(6,12$ and $20 \mathrm{kt})$.

In addition, a multiple linear regression model is used to improve the TC intensity forecast using DAV-Bands forecast, latitude, storm age (calculated as the time since the TC became a tropical storm), sea surface temperatures
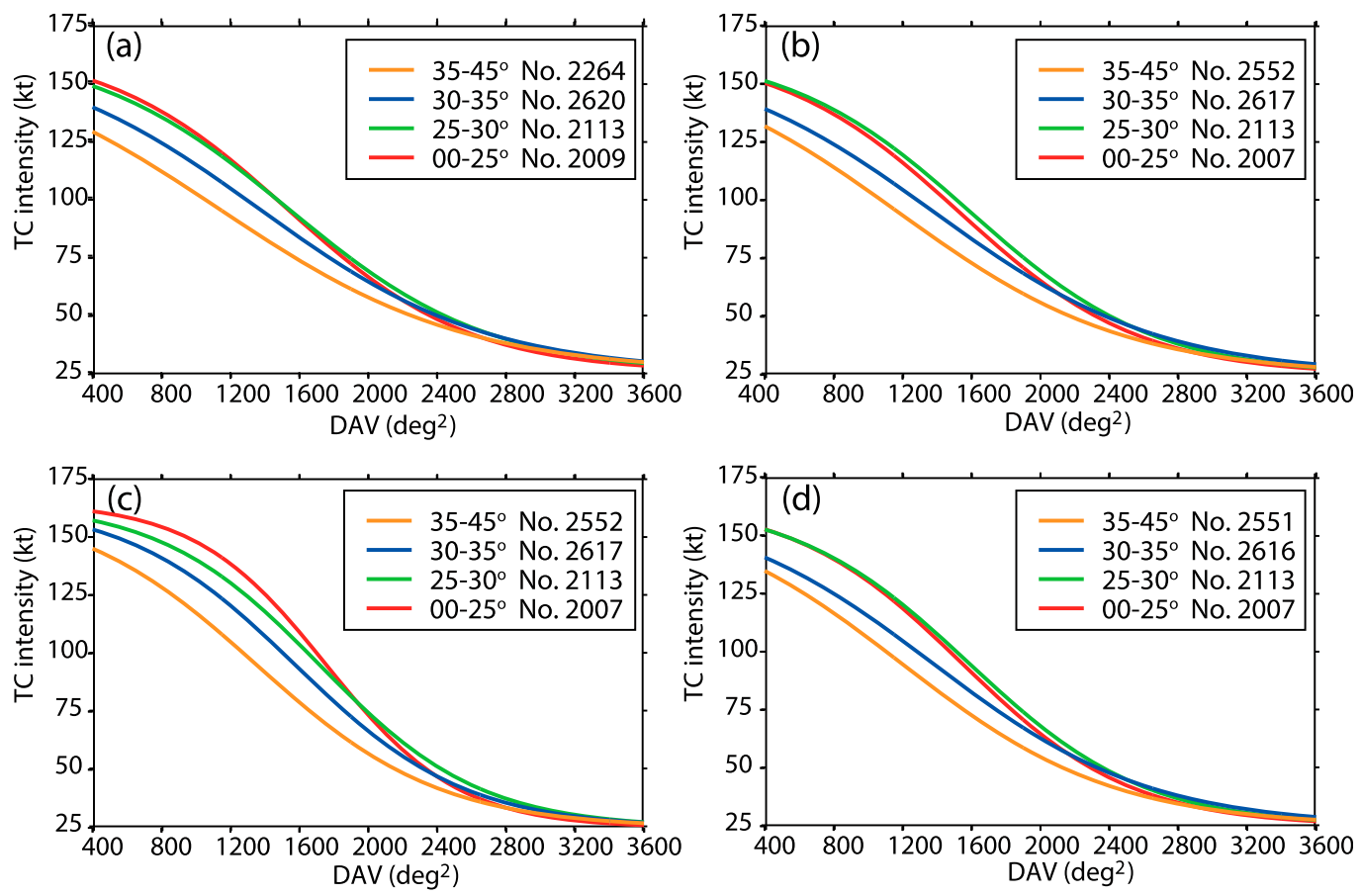

FIG. 6. The sigmoid curves for satellite observation angles of $0^{\circ}-25^{\circ}, 25^{\circ}-30^{\circ}, 30^{\circ}-35^{\circ}$, and $35^{\circ}-45^{\circ}$ for (a) IR, (b) $\mathrm{WV}$, (c) $3.9 \mu \mathrm{m}$, and (d) $13.3 \mu \mathrm{m}$ for the 24 -h intensity forecast using the 12 -h mean DAV. 

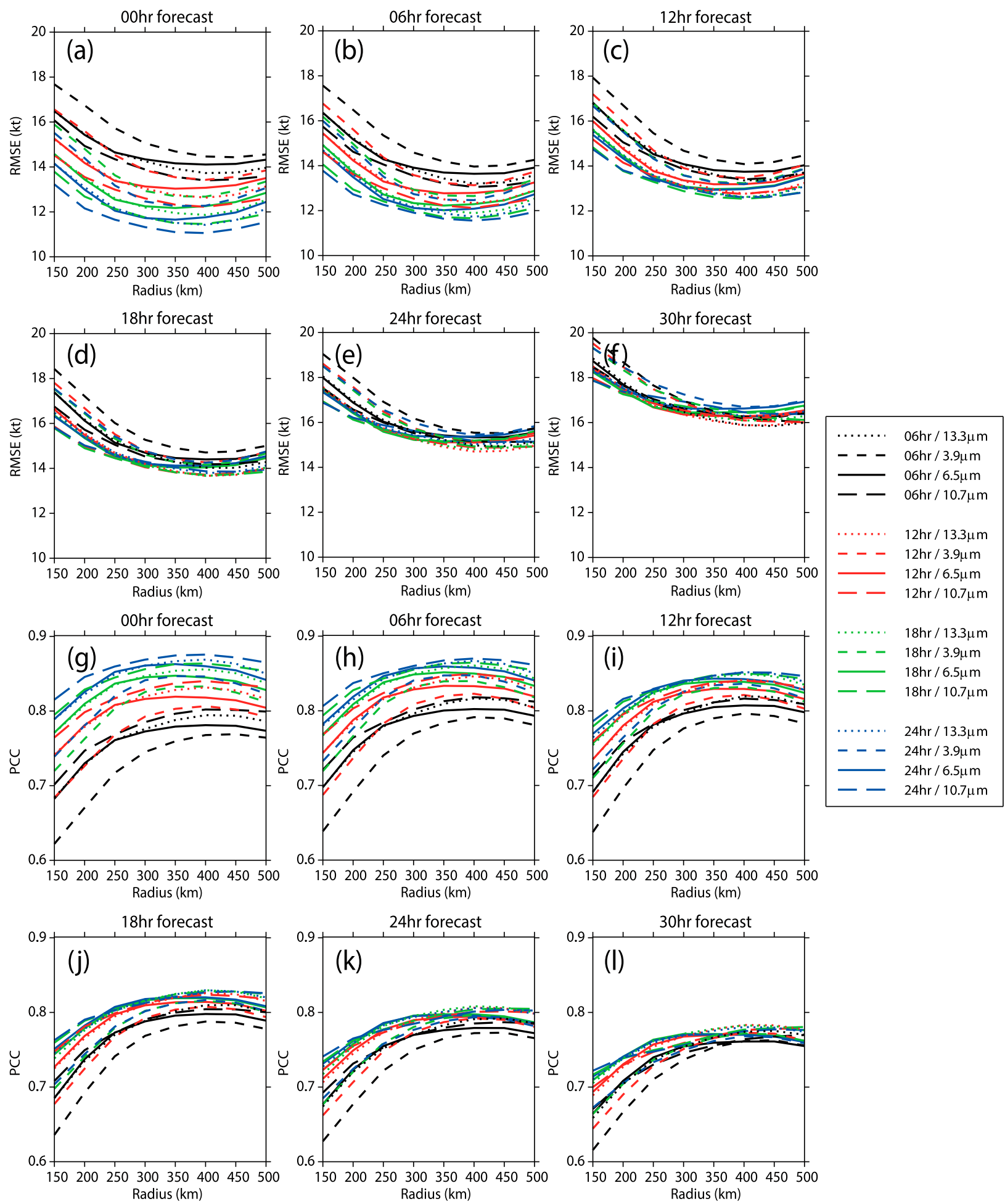

FIG. 7. The (a)-(f) RMSE and (g)-(1) PCC of the 0-, 6-, 12-, 18-, 24-, and 30-h forecast at eight different radii of DAV calculation using the 6, 12, 18 and 24-h mean DAV, respectively. 
(a)

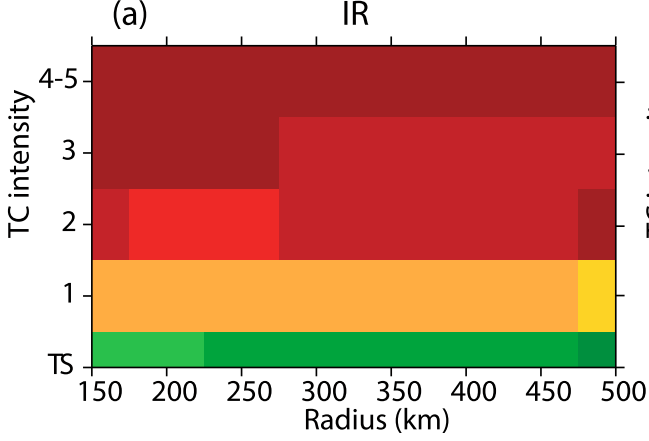

(c)

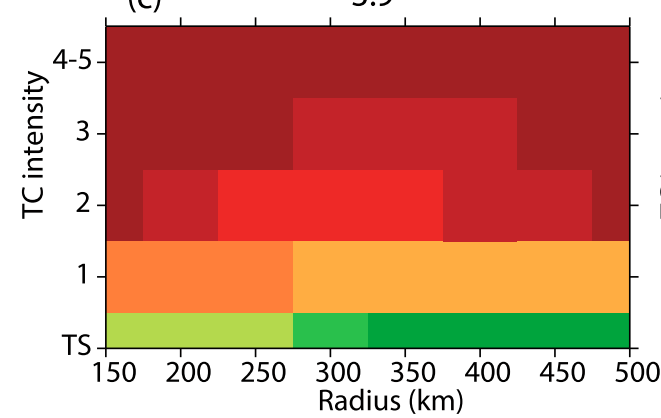

(b)

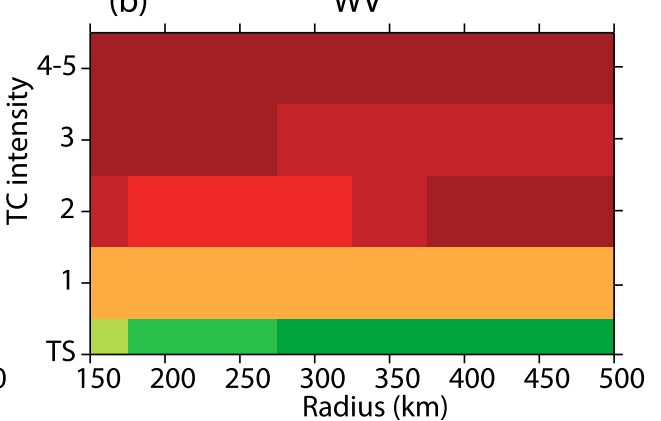

(d)

13.3

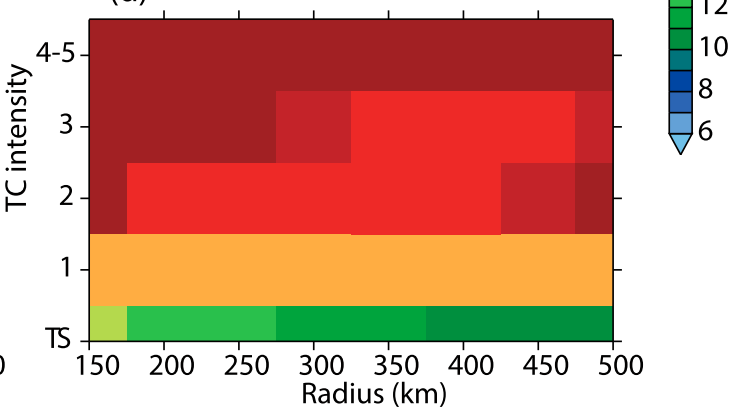

FIG. 8. The RMSE of the 24-h intensity forecast using the 12-h mean DAV calculated using eight different radii banded into six TC intensity categories for the (a) IR, (b) WV, (c) $3.9-\mu \mathrm{m}$, and (d) $13.3-\mu \mathrm{m}$ bands.

(SST), and 128 variables from GOES imagery including average TBB, minimum TBB, TBB gradience, and DAV forecast over the eight areas with a radius extending from 150 to $500 \mathrm{~km}$ at $50 \mathrm{~km}$. Potential predictors aside from the DAV value are selected as past research has found they are related to TC intensity, and all predictors are $24 \mathrm{~h}$ before the TC forecast time. The prediction equation for the multiple linear regression model is

$$
y=b_{0}+b_{1} x_{1}+b_{2} x_{2}+\cdots+b_{k} x_{k},
$$

where $b_{0}$ is the intercept or the regression coefficient, $x$ is a predictor variable, and each of the $k$ predictor variables has its own coefficient $b_{k}$, analogous to the slope of a line (Wilks 2006, 179-252). The preliminary step consists of a screening regression known as forward selection, where each of the predictors is numerically tested for the strength of their linear relationship to the predictand. After the predictor with the best linear relationship is selected, the process is repeated with the remaining variables. The process continues until the predictors display diminished improvements within the regression equation. Once additional predictors improve the regression equation by less than $1 \%$, they are ignored. For the $24-\mathrm{h}$ TC intensity forecast model, SST and latitude were the most valuable predictors after the 24-h TC intensity forecast using DAV-Bands. Compared to the forecast using IR imagery and four-band imagery, the RMSE and MAE decreased to 13.7 and $10.9 \mathrm{kt}$ using the regression model, respectively. This is very close to the NHC errors (Fig. 11). The 24-h forecast MAE of the Decay-SHIFOR model during 2009-15 is $10.0 \mathrm{kt}$, which is lower than for the DAV. However, during weakening periods the MAE for Decay-SHIFOR is $11.0 \mathrm{kt}$ while it is $10.4 \mathrm{kt}$ for DAVBands, suggesting that the skill space of the DAV is about $5.5 \%$ better relative to Decay-SHIFOR during weakening periods.

\section{Summary and conclusions}

Using the DAV technique, the lead time of cloud structure changes in satellite imagery to TC intensity is used to investigate short-term TC intensity forecasting over the North Atlantic basin. Using IR imagery during 2009-15, the 6-30-h TC intensity forecast based on the

TABLE 5. The 24-h intensity forecast errors (DAV-IR/multiradii DAV) by TC intensity category. All differences between the two forecast errors were significant at the 0.01 level using a Student's $t$ test except for the hurricane categories 3-5.

\begin{tabular}{lccc}
\hline \hline \multicolumn{1}{c}{ TC intensity } & RMSE (kt) & MAE (kt) & MRE (\%) \\
\hline Tropical storms & $11.1 / 11.0$ & $9.1 / 8.9$ & $19.6 / 19.3$ \\
Hurricane categories 1-2 & $17.5 / 17.1$ & $14.7 / 13.9$ & $19.3 / 18.3$ \\
Hurricane categories 3-5 & $21.3 / 20.7$ & $17.4 / 16.9$ & $15.4 / 15.1$ \\
All & $15.0 / 14.5$ & $11.9 / 11.4$ & $19.2 / 18.5$ \\
\hline
\end{tabular}



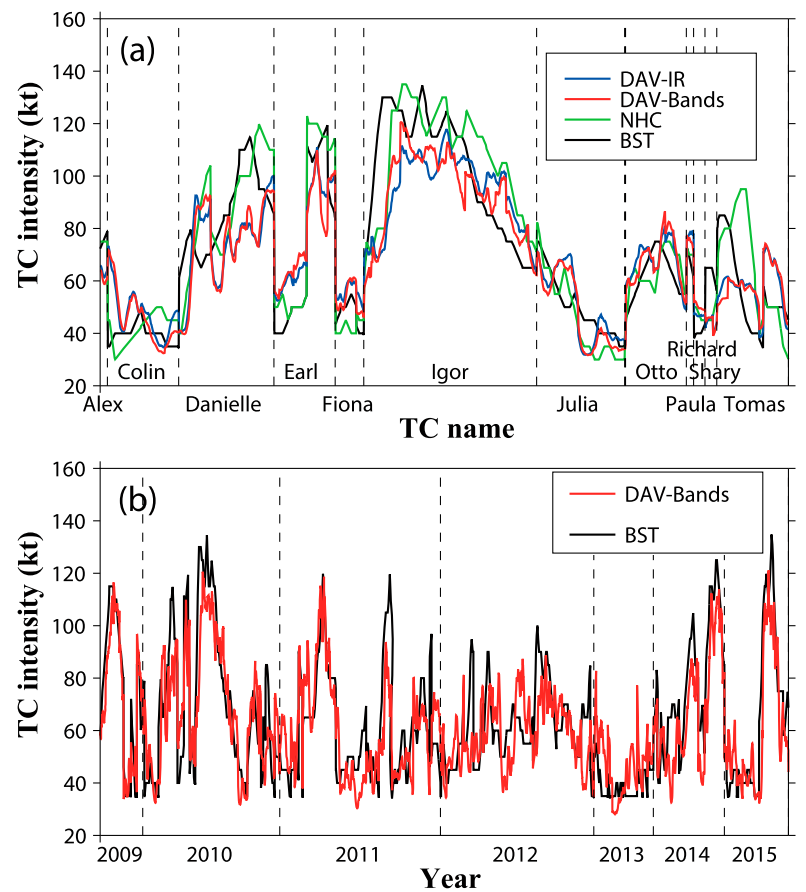

FIG. 9. (a) As in Fig. 4, but the multiband DAV 24-h TC intensity forecast is added. (b) As in (a), but for 7870 samples ( $\geq 34 \mathrm{kt}$ ) during 2009-15 and DAV-IR and NHC are excluded. The samples are split evenly and do not represent a time-continuous plot.

DAV technique is calculated and compared to the NHC forecast, and an improved 24-h TC intensity forecast using multiband imagery is described and evaluated in this study. The results show that:

1) The DAV of a TC changes ahead of the TC intensity, with a lead time within $36 \mathrm{~h}$, consistent with previous results of theoretical and numerical experiments. To filter the diurnal and semidiurnal oscillations in the DAV time series, a time mean DAV is used from 6 to $24 \mathrm{~h}$ (i.e., within the $36-\mathrm{h}$ window). The study shows that for a longer lead time intensity forecast, a shorter time mean DAV should be used and vice versa. For a $24-\mathrm{h}$ intensity forecast, a $12-\mathrm{h}$ mean DAV performs the best.
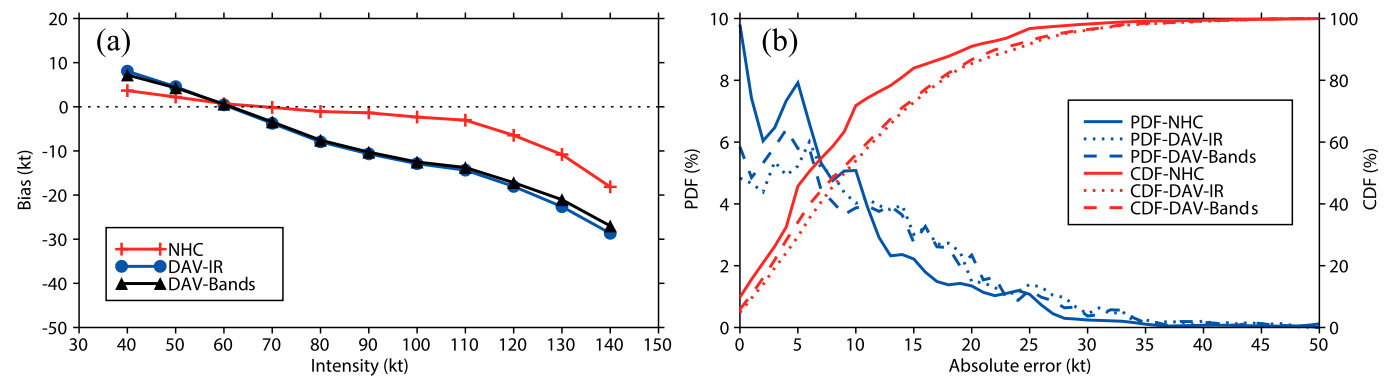

FIG. 10. As in Fig. 5, but with the 24-h intensity forecast using the DAV multiband technique added (black).
2) For IR imagery, a radius of $400 \mathrm{~km}$ of calculation provides the most accurate $24-\mathrm{h}$ TC intensity forecast with a PCC, RMSE and MAE of $0.8,14.8 \mathrm{kt}$, and $11.8 \mathrm{kt}$, respectively, over the 7-yr period. Statistically, the DAV-IR 24-h intensity forecast is close to or better than other techniques, but slightly worse than the NHC official intensity forecast, especially for hurricane categories $2-5$, as the NHC forecasts incorporating many other sources of information. In particular, the DAV forecast technique appears to perform better than the NHC official forecast during TC weakening periods and can provide complementary information to improve TC intensity forecasts.

3) The IR, WV, 3.9- $\mu \mathrm{m}$, and $13.3-\mu \mathrm{m}$ bands provide additional information on different atmospheric characteristics and are combined to enhance the DAV TC intensity estimation. The IR band performs better than the other bands when the forecast lead time is within $12 \mathrm{~h}$, but when the forecast time is greater than $18 \mathrm{~h}$, the $13.3-\mu \mathrm{m}$ DAV outperforms the other bands. An improved TC intensity forecast is obtained by incorporating all four satellite bands.

4) Using the DAV multiband 24-h TC intensity forecast and SST and TC latitude as predictors in a linear regression model, the resulting RMSE and MAE are 13.7 and $10.9 \mathrm{kt}$, respectively, comparable to 12.0 and $9.0 \mathrm{kt}$ for the $\mathrm{NHC}$ official forecast. In particular, the skill of the regression model is about $+5.5 \%$ relative to Decay-SHIFOR during weakening periods.

This investigation demonstrates that there is a strong relationship between satellite-based DAV and both the current and future storm intensity. Based on the DAV technique, satellite imagery can be used to directly predict short-term TC intensity. Similar to real-time DAV-based TC intensity estimation (Ritchie et al. 2012; $\mathrm{Hu}$ et al. 2019), the DAV intensity forecast technique produces the largest bias for strong hurricanes. A better fit curve to represent the DAV-TC intensity relationship would improve this bias and will continue to be worked on. The incorporation of multiple satellite bands was done in a relatively simple manner in this study. 


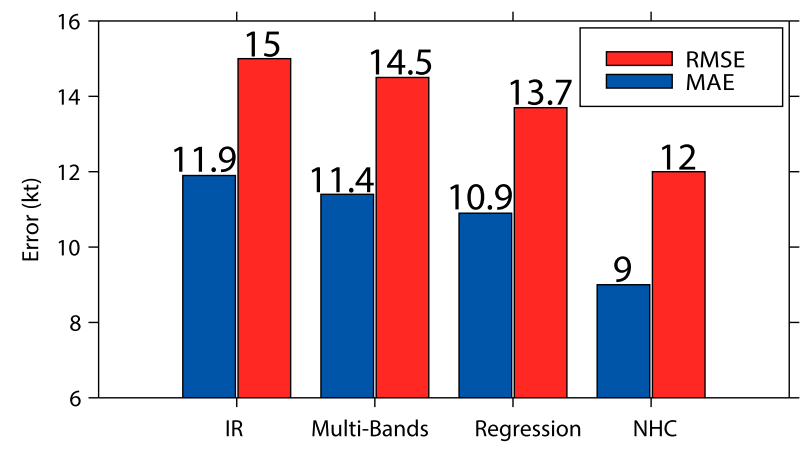

FIG. 11. The 24-h TC intensity forecast errors using DAV-IR, multiband DAV, and the DAV regression model, compared with NHC.

A better method, for example the least squares method, to obtain the best combination of multiple bands and multiple areas of calculation is being explored. Furthermore, based on the diurnal character of each band, using the high correlation local time to obtain the best combination of bands is also possible. Finally, MW can penetrate into precipitating clouds, and measure features that can be used to better estimate TC intensity (e.g., Bankert and Tag 2002; Brueske and Velden 2003; Demuth et al. 2004, 2006; Jiang et al. 2019), and to adjust the intensity estimation errors in IR methods, especially within the TC intensity ranges most affected by the CDO plateau weak bias (Olander and Velden 2019). The aim is to produce an improved multispectral DAV technique for short-term TC intensity forecast for operational use. The DAV method provides valuable, additional, objective information that can inform tropical cyclone forecasts, especially during weakening periods, and could be used either as a primary source of information in other basins where the quality and quantity of observational data are not as great as in the North Atlantic basin or in combination with other techniques.

Acknowledgments. Best track data and forecast data of TCs over the North Atlantic basin were obtained from the NOAA NHC (http://www.nhc.noaa.gov). This study was funded by the National Natural Science Foundation of China (Grant Nos. 41575045, 41205030, and 41175046).

\section{REFERENCES}

Arnold, C. P., 1974: Tropical cyclone position and intensity analysis using satellite data. First Weather Wing Pamphlet, IWWP 105-10, Dept. of the Air Force, 97 pp.

Bankert, R. L., and P. M. Tag, 2002: An automated method to estimate tropical cyclone intensity using SSM/I imagery. J. Appl. Meteor., 41, 461-472, https://doi.org/10.1175/15200450(2002)041<0461:AAMTET>2.0.CO;2.
Brueske, K., and C. Velden, 2003: Satellite-based tropical cyclone intensity estimation using the NOAA-KLM series Advanced Microwave Sounding Unit (AMSU). Mon. Wea. Rev., 131, 687-697, https://doi.org/10.1175/1520-0493(2003)131<0687: SBTCIE $>2.0 . C O ; 2$.

Cecil, D. J., and E. J. Zipser, 1999: Relationships between tropical cyclone intensity and satellite-based indicators of inner core convection: $85-\mathrm{GHz}$ ice-scattering signature and lightning. Mon. Wea. Rev., 127, 103-123, https://doi.org/10.1175/15200493(1999)127<0103:RBTCIA > 2.0.CO;2.

Demuth, J. L., M. De Maria, J. A. Knaff, and T. H. Vonder Haar, 2004: Evaluation of Advanced Microwave Sounding Unit tropical-cyclone intensity and size estimation algorithms. J. Appl. Meteor., 43, 282-296, https://doi.org/10.1175/15200450(2004)043<0282:EOAMSU > 2.0.CO;2.

,-- , and -2006 : Improvement of Advanced Microwave Sounding Unit tropical cyclone intensity and size estimation algorithms. J. Appl. Meteor. Climatol., 45, 1573-1581, https:// doi.org/10.1175/JAM2429.1.

Dunion, J. P., C. D. Thorncroft, and C. S. Velden, 2014: The tropical cyclone diurnal cycle of mature hurricanes. Mon. Wea. Rev., 142, 3900-3919, https://doi.org/10.1175/MWR-D-13-00191.1.

,-- , and D. S. Nolan, 2019: Tropical cyclone diurnal cycle signals in a hurricane nature run. Mon. Wea. Rev., 147, 363388, https://doi.org/10.1175/MWR-D-18-0130.1.

Dunn, G. E., and B. I. Miller, 1960: Atlantic Hurricanes. Louisiana State University Press, 123 pp.

Dvorak, V.F., 1975: Tropical cyclone intensity analysis and forecasting from satellite imagery. Mon. Wea. Rev., 103, 420-430, https:// doi.org/10.1175/1520-0493(1975)103<0420:TCIAAF>2.0.CO;2.

Glass, M., and G. W. Felde, 1992: Intensity estimation of tropical cyclones using SSM/I brightness temperatures. Preprints, Sixth Conf. on Satellite Meteorology and Oceanography, Atlanta, GA, Amer. Meteor. Soc., J8-J10.

Gray, W. M., 1979: Hurricanes: Their formation, structure and likely role in the tropical circulation. Meteorology over the Tropical Oceans, D. B. Shaw, Ed., Royal Meteorological Society, 155-218.

Harr, P. A., D. Arwender, and S. C. Jones, 2008: Predictability associated with the downstream impacts of the extratropical transition of tropical cyclones: Methodology and a case study of Typhoon Nabi (2005). Mon. Wea. Rev., 136, 3205-3225, https://doi.org/10.1175/2008MWR2248.1.

Herndon, D., and C. Velden, 2014: An update on tropical cyclone intensity estimation from satellite microwave sounders. 31st Conf. on Hurricanes and Tropical Meteorology, San Diego, CA, Amer. Meteor. Soc., 34, https://ams.confex.com/ams/ 31Hurr/webprogram/Paper244770.html.

Hillger, D. W., and T. J. Schmit, 2010: The GOES-14 science test: Imager and sounder radiance and product validations. NOAA Tech. Rep. NESDIS 131, Washington, D.C., 106 pp.

Hu, L., E. A. Ritchie, and J. S. Tyo, 2019: Influence of satellite observation angle on tropical cyclone intensity estimation using the deviation angle variance technique. IGARSS 2019-2019 IEEE Int. Geoscience and Remote Sensing Symp., Yokohama, Japan, IEEE, https://doi.org/10.1109/IGARSS.2019.8898743.

Jiang, H., 2012: The relationship between tropical cyclone intensity change and the strength of inner-core convection. Mon. Wea. Rev., 140,1164-1176, https://doi.org/10.1175/MWR-D-11-00134.1.

— C. Tao, and Y. Pei, 2019: Estimation of tropical cyclone intensity in the North Atlantic and Northeastern Pacific basins using TRMM satellite passive microwave observations. J. Appl. Meteor. Climatol., 58, 185-197, https://doi.org/10.1175/JAMCD-18-0094.1. 
Jones, T. A., D. Cecil, and M. Demaria, 2006: Passivemicrowave-enhanced Statistical Hurricane Intensity Prediction Scheme. Wea. Forecasting, 21, 613-635, https://doi.org/10.1175/ WAF941.1.

Kieper, M., and H. Jiang, 2012: Predicting tropical cyclone rapid intensification using the $37 \mathrm{GHz}$ ring pattern identified from passive microwave measurements. Geophys. Res. Lett., 39, L13804, https://doi.org/10.1029/2012GL052115.

Knaff, J. A., D. P. Brown, J. Courtney, G. M. Gallina, and J. L. Beven, 2010: An evaluation of Dvorak technique-based tropical cyclone intensity estimates. Wea. Forecasting, 25, 1362-1379, https://doi.org/10.1175/2010WAF2222375.1.

Kossin, J. P., 2002: Daily hurricane variability inferred from goes infrared imagery. Mon. Wea. Rev., 130, 2260-2270, https://doi.org/10.1175/1520-0493(2002)130<2260:DHVIFG> 2.0.CO;2.

Kurihara, Y., and R. E. Tuleya, 1974: Structure of a tropical cyclone developed in a three-dimensional numerical simulation model. J. Atmos. Sci., 31, 893-919, https://doi.org/10.1175/ 1520-0469(1974)031<0893:SOATCD > 2.0.CO;2.

McBride, J., 1995: Tropical cyclone formation. Global view of tropical cyclones. WMO Tech. Rep. TCP-38, 289 pp.

Olander, T. L., and C. S. Velden, 2007: The advanced Dvorak technique: Continued development of an objective scheme to estimate tropical cyclone intensity using geostationary infrared satellite imagery. Wea. Forecasting, 22, 287-298, https:// doi.org/10.1175/WAF975.1.

—_, and —, 2009: Tropical cyclone convection and intensity analysis using differenced infrared and water vapor imagery. Wea. Forecasting, 24, 1558-1572, https://doi.org/10.1175/ 2009WAF2222284.1.

_, and —_, 2019: The Advanced Dvorak Technique (ADT) for estimating tropical cyclone intensity: Update and new capabilities. Wea. Forecasting, 34, 905-922, https://doi.org/10.1175/ WAF-D-19-0007.1.

Piñeros, M. F., E. A. Ritchie, and J. S. Tyo, 2008: Objective measures of tropical cyclone structure and intensity change from remotely sensed infrared image data. IEEE Trans. Geosci. Remote Sens., 46, 3574-3580, https://doi.org/10.1109/ TGRS.2008.2000819.
,-- , and -2011 : Estimating tropical cyclone intensity from infrared image data. Wea. Forecasting, 26, 690-698, https://doi.org/10.1175/WAF-D-10-05062.1.

Riehl, H., 1954: Tropical Meteorology. McGraw-Hill, 392 pp

Ritchie, E. A., G. Valliere-Kelley, M. F. Piñeros, and J. S. Tyo, 2012: Tropical cyclone intensity estimation in the North Atlantic basin using an improved deviation angle variance technique. Wea. Forecasting, 27, 1264-1277, https://doi.org/ 10.1175/WAF-D-11-00156.1.

— K. M. Wood, O. G. Rodríguez-Herrera, M. F. Piñeros, and J. S. Tyo, 2014: Satellite-derived tropical cyclone intensity in the North Pacific Ocean using the deviation-angle variance technique. Wea. Forecasting, 29, 505-516, https://doi.org/ 10.1175/WAF-D-13-00133.1.

Rosenthal, S. L., 1978: Numerical simulation of tropical cyclone development with latent heat release by the resolvable scales. I: Model description and preliminary results. J. Atmos. Sci., 35, 258-271, https://doi.org/10.1175/1520-0469(1978)035<0258: NSOTCD $>2.0 . \mathrm{CO} ; 2$.

Sebastien, L., and Coauthors, 2018: Intensity change: Operational perspectives. Int. Workshop on Tropical Cyclones, WMO, La Réunion, France, 29 pp., https://www.wmo.int/pages/prog/ arep/wwrp/tmr/documents/IWTC-9_Subtopic_3-3.pdf.

Velden, C., T. Olander, and R. Zehr, 1998: Development of an objective scheme to estimate tropical cyclone intensity from digital geostationary satellite infrared imagery. Wea. Forecasting, 13, 172-186, https://doi.org/10.1175/1520-0434(1998)013<0172: DOAOST $>2.0 . \mathrm{CO} ; 2$.

Wilks, D. S., 2006: Statistical Methods in the Atmospheric Sciences. 2nd ed. International Geophysics Series, Vol. 100, Academic Press, 648 pp.

Wimmers, A., C. S. Velden, and J. Cossuth, 2019: Using deep learning to estimate tropical cyclone intensity from satellite passive microwave imagery. Mon. Wea. Rev., 147, 2261-2282, https://doi.org/10.1175/MWR-D-18-0391.1.

Wood, K. M., O. G. Rodriguez-Herrera, E. A. Ritchie, M. F. Pineros, I. A. Hernandez, and J. S. Tyo, 2015: Tropical cyclogenesis detection in the North Pacific using the deviation angle variance technique. Wea. Forecasting, 30, 1663-1672, https://doi.org/10.1175/WAF-D-14-00113.1. 